\title{
Plastic deformation of recrystallized tungsten-potassium wires: constitutive deformation law in the temperature range $22-600^{\circ} \mathrm{C}$
}

D. Terentyev ${ }^{1}$, J. Riesch ${ }^{2}$, S. Lebediev ${ }^{3}$, T.Khvan $^{3}$, A. Zinovev ${ }^{1,4}$, M. Rasiński ${ }^{5}$, A. Dubinko ${ }^{1}$, J.W. Coenen ${ }^{5}$

${ }^{1}$ Structural Materials Group, Institute of Nuclear Materials Science, SCK·CEN, Mol, 2400, Belgium

${ }^{2}$ Max-Planck-Institut für Plasmaphysik, 85748 Garching, Germany

${ }^{3}$ V.N. Karazin Kharkiv National Universit, 4 Svobody Sq., Kharkiv, 61022, Ukraine

${ }^{4}$ iMMC, Université catholique de Louvain, Louvain-Ia-Neuve, 1348, Belgium

${ }^{5}$ Forschungszentrum Jülich GmbH, Institut für Energie- und Klimaforschung - Plasmaphysik, Partner of the Trilateral Euregio Cluster (TEC), 52425 Jülich,Germany

\section{Abstract}

Recent efforts dedicated to the mitigation of tungsten (W) brittleness have demonstrated that tungsten fiber-reinforced composites acquire extrinsic toughening even at room temperature, which is due to the outstanding strength of W wires. However, high temperature operation/fabrication of the fiber-reinforced composite might result in the degradation of the mechanical properties of $\mathrm{W}$ wires. To address this, we investigate mechanical and microstructural properties of potassium-doped tungsten wires, being heat treated at $2300^{\circ} \mathrm{C}$ and tested in temperature range $22-600^{\circ} \mathrm{C}$. Based on the microscopic analysis, the engineering deformation curves are converted into actual stress - strain dataset, accounting for the local necking. The analysis demonstrates that local strain in the necking region can reach up to $50 \%$ and the total elongation monotonically increases with temperature, while the ultimate tensile strength goes down. Preliminary transmission electron microscopy analysis using FIB-cut lamella from the necking region revealed the presence of curved dislocation lines in the sample tested at $300 \mathrm{C}$, proving that plastic deformation occurred by dislocation glide.

Keywords: Tungsten, tungsten wire, plasticity, potassium doped.

\section{Introduction}

Tungsten (W) is currently the main candidate material for the first wall of a fusion reactor as it is resilient against erosion and exhibits low tritium retention as well as a very high melting point and a good thermal conductivity [1]. However as a typical bcc metal, tungsten features intrinsic brittleness up to a temperature of about $200-300{ }^{\circ} \mathrm{C}[2,3]$ and up to above $900{ }^{\circ} \mathrm{C}$ after the annealing at high temperature [4]. In addition, $\mathrm{W}$ is prone to operational embrittlement e.g. by grain coarsening [5] or/and neutron irradiation [6].

Extensive work has been done to qualify current materials with respect to these issues for ITER. This is especially true for $W$ used as the first wall and divertor material (see $[1,7,8]$ and references therein). For the next step devices, e.g. DEMO, or a future fusion reactor the limits on power exhaust, availability and lifetime are quite more stringent. Extensive studies and material programs [9-11] 
have already been performed hence it is assumed that the boundary conditions [12] to be fulfilled for the materials are in many cases exceed the technical feasibility limits as set today. Efforts to establish new advanced options for plasma-facing material/components are moving forward focusing on crack resilient materials with low activation, minimal tritium uptake, long lifetime and low erosion. The operational gap ( $350-600^{\circ} \mathrm{C}$ ) between materials for cooling structures e.g. $\mathrm{Cu}$, and the plasmafacing materials needs to be bridged as well $[7,13]$.

Tungsten fiber-reinforced composites $\left(\mathrm{W}_{\mathrm{f}} / \mathrm{W}\right)$ overcome the brittleness problem of bulk tungsten by utilizing extrinsic toughening mechanisms similar to ceramic matrix composites [14]. The proof of extrinsic toughening in such a composite system has been shown in the past years at the Max-PlanckInstitute for Plasma Physics, Garching (IPP) [15]. $W_{f} / W$ composites consist of tungsten fibers made of commercially drawn tungsten wire embedded in a tungsten matrix produced either by a chemical process [16] or by powder metallurgy [17].

The structural integrity of $\mathrm{W}_{\mathrm{f}} / \mathrm{W}$ composites are based on the exceptional properties of the tungsten wire used as fiber reinforcement: pure as well as potassium doped tungsten wire shows exceptional ductility [18] and very high strength [19] even at room temperature in contrast to conventional bulk tungsten being brittle at room temperature [2]. These are ideal properties facilitating the toughening of $\mathrm{W}_{\mathrm{f}} / \mathrm{W}$ as the high strength is important for the bridging effect and ductile deformation allows the dissipation of a substantial amount of energy [20]. This success gave a push to study properties of the tungsten wire solely, and in particular investigation of the mechanical response at elevated temperatures.

Recently, a set of W wires with and without potassium doping was studied in [21] by mechanical tests performed up to $600^{\circ} \mathrm{C}$. For the as-drawn wire, the potassium doping practically did not change the response to the mechanical load. The fracture occurred by the elongation and delamination of sub-grains (elongated in the direction of wire axis) showing the knife-edge necking fracture typically observed for $\mathrm{W}$ wire [22]. Both fracture stress and fracture strain monotonically decreased with increasing the test temperature. The necking was essentially localized, and the length of a neck was about 150-200 $\mu \mathrm{m}$ being comparable with the initial diameter of the wire. No diffuse necking process occurred during the deformation of the wire in the as-fabricated condition.

$2300^{\circ} \mathrm{C}$ annealed potassium-doped wire was seen to have much lower yield and fracture stress. The fracture mechanism was also different, namely: cleavage at $100{ }^{\circ} \mathrm{C}$ and ductile necking above $300{ }^{\circ} \mathrm{C}$. The change of the deformation mechanism and thereby increased elongation was attributed to the onset of the 3D plastic deformation by movement of screw dislocations. The total elongation of the wire before the fracture was much higher as compared to the as-drawn wires, moreover the plastic deformation was more pronounced, as revealed by post mortem microscopic study. Hence, the understanding of the local deformation and extraction of the post-necking stress-strain characteristics of the annealed wire is needed to complete this work.

In the following, we continue our study and perform microstructural analysis of the deformed fibers to deduce geometric parameters of the necked regions and reconstruct the post-necking stress strain (PNSS) relationship thus extracting the constitutive law. The results are then summarized in a convenient format to be used by a conventional finite element code (e.g. Abaqus) to model plastic deformation of the fibers. 


\section{Experimental details}

Drawn potassium doped (60-75 ppm) tungsten wire, similar to the wire used in $[21,23]$ was provided by the OSRAM GmbH, Schwabmünchen. The diameter of the doped wire was measured to be $148.7 \pm 0.2 \mu \mathrm{m}$ [23]. Measurements were performed by high resolution optical microscope. The Kdoped wire was cut into pieces of $100 \mathrm{~mm}$ and these were annealed at $2300{ }^{\circ} \mathrm{C}$. To perform the annealing, the wire was straightened prior to cutting. The straightened and cut wire pieces were then annealed in a tube furnace under hydrogen atmosphere at OSRAM GmbH. During this process the samples were placed on a shovel (carbon free) and kept at $2300^{\circ} \mathrm{C}$ for $30 \mathrm{~min}$.

In order to clamp, the ends of the wire pieces (called fibers in the following) were clutched by two parallel mirror-polished stainless steel plates by applying the minimum force required to carry out the mechanical test and avoid deformation near the clamping plates or sliding of the wires between the plates. The gauge section was $30 \mathrm{~mm}$. The sample holder was equipped with a guide rail to ensure perfect alignment. More details about testing procedure can be found in our recent work [21].

To ensure constant temperature during the test, the gauge section of the sample and inner parts of the holders were placed inside a cylindrical furnace. The temperature of the sample was measured by a thermocouple, connected to a digital voltmeter. Accuracy of the temperature measurement was $\sim 1 \mathrm{~K}$. The sample were tested in air. Prior to proceed with the loading, the system was equilibrated at the desired test temperature for 30 mins.

The deformation on the sample is applied via a pull rod driven by an electrical gear box, with a maximum load of $0.2 \mathrm{kN}$. A constant displacement with a cross-head speed of $5 \mu \mathrm{m} / \mathrm{s}$ was applied until fracture. The load, measured by a strain gauge, was registered with a frequency of $0.3 \mathrm{~Hz}$. The initial and final (i.e. after fracture) length of each sample was determined by the horizontal optical comparator with a precision of $1 \mu^{1}$. The relative error on the measurement of the pull rod displacement is $\pm 0.1 \%$ and the absolute error on the stress measurement (for the strain region where the cross-section of the fiber remains constant) is $15 \mathrm{MPa}$.

After the test, the surface of the fractured samples was inspected by SEM on both ends. This allowed one to clarify the morphology of the fracture surface and assist the discussion on the deformation mode. The employed scanning electron microscope was a JEOL JSM-6610LV (JEOL, Tokyo, Japan) and operating conditions employed $20 \mathrm{kV}$ accelerating voltage and $12-20 \mathrm{~mm}$ working distance. All SEM images presented in this work were acquired using a secondary electron (SE) detector. The necking region of each fractured sample was investigated in an optical microscope (Leica) to obtain the necking geometry, needed to reconstruct the stress - strain relationship in the post-necking region accounting for the non-uniform reduction of the wire cross-section. The necking diameter was also measured using SEM to refine/validate the measurements done by the optical microscope. The methodology used to convert the engineering stress-strain into actual stress-strain data is described in the following section, following the presentation of the engineering data.

\footnotetext{
${ }^{1}$ The fiber ends are placed in the special bed, where one end is abut and the length is measured by optical microscopy.
} 


\section{Results and discussion}

The test matrix is given in Table 1. At least five valid tests per condition were performed. Here, we provide examples of stress-strain curves and micrographs of few selected fibers.

Table 1. Test matrix and ID for the fibers inspected by SEM whose micrographs are presented below.

\begin{tabular}{|l|c|c|c|c|c|}
\hline Type of wire & $100^{\circ} \mathrm{C}$ & $200^{\circ} \mathrm{C}$ & $300^{\circ} \mathrm{C}$ & $500^{\circ} \mathrm{C}$ & $600^{\circ} \mathrm{C}$ \\
\hline $\begin{array}{l}\mathrm{K} \text {-doped } \\
\begin{array}{l}2300^{\circ} \mathrm{C} \\
\text { annealed }\end{array}\end{array}$ & $\mathrm{SEM}=\mathrm{C} 20$ & $\mathrm{SEM}=\mathrm{C} 18$ & $\mathrm{SEM}=\mathrm{C} 11$ & $\begin{array}{l}\mathrm{SEM}=\mathrm{C} 22, \\
\mathrm{C} 13\end{array}$ & $\mathrm{SEM}=\mathrm{C} 16$ \\
\hline
\end{tabular}

Fig.1(a) collects typical stress-strain curves obtained for the fibers tested at different temperatures. At room temperature, the wire does not show any yield and breaks in the elastic mode of the deformation, hence we have not included it in the figure. The low-strain deformation region is shown in Fig.1(b) to illustrate that the irreversible plastic deformation begins before the engineering strain reaches $0.2 \%$ (indicated by a dashed line). The deflection from the straight line (i.e. purely elastic deformation) emerges around $0.005-0.01 \%$ deformation strain. One can also clearly see the presence of the yield drop. In fact, the yield drop was registered in all the samples, but its amplitude decreases with the test temperature and is therefore not visible for the higher temperature curves. The "yield drop" is likely to be associated with the presence of interstitial impurities [24], mostly carbon. At this point, it is impossible to identify the actual mechanism responsible for the observed yield drop unambiguously. It is known that the wires were drawn from the technically pure $W$ which contained at least few tens of ppm of carbon. The thermal annealing was performed 2300C, and should have resulted in the removal of the most of grain boundary interfaces as well as dislocation networks. While potassium is expected to remain in clusters (precipitates) not being dissolved in the matrix. Correspondingly, the retained interstitial carbon atoms might have re-arranged to segregate at the remaining dislocations and grain boundaries, overall resulting in the suppression of the dislocation glide/emission causing the occurrence of the upper and lower yield point.

For the wires tested at 100 and $200 \mathrm{C}$, the maximum engineering stress was reached shortly after the deformation strain reached about $0.005-0.01 \%$, and therefore we use this level as the onset of the diffuse necking and recalculate the actual stress and strain, as explained below. If the particular test does not demonstrate diffuse necking, $0.2 \%$ of engineering strain is taken as the onset of the plastic deformation, as for instance is the case for $500 \mathrm{C}$ test in Fig.1. 

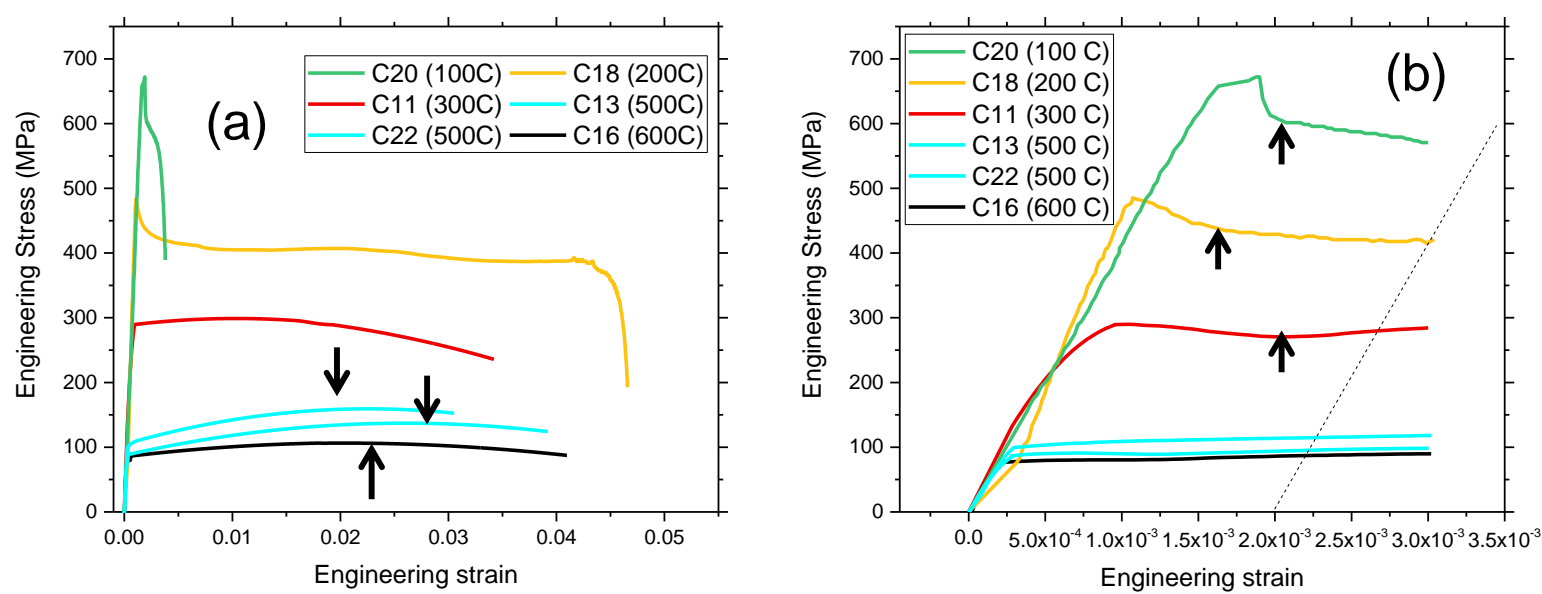

Fig.1. (a) Full engineering stress-strain curves, (b) zoom up in the low deformation range to underline that the yield occurs essentially prior $0.2 \%$ deformation threshold (as indicated by a dashed line). The data for $500 \mathrm{C}$ is presented to demonstrate the scattering of the stress-strain response in terms of both ultimate tensile strength and total elongation. The black arrow defines the strain at which the onset of necking is considered to take place.

Once the maximum engineering stress is reached, we assume that the necking process onsets and then only the local region of the wire experiences plastic deformation (indicated by black arrows in Fig.2). By measuring the geometrical parameters of the tested wire we identify the length of the necking region and the diameter of the fibers at the fracture point, such as schematically shown in Fig.2(a). By using digital optical microscope, it is possible to measure the required parameters for each part of the tested fibers, see for example Fig.2 (b) and (c).

To ensure the accuracy, we employed SEM to accurately measure the dimensions of the ends of the fractured fibers, for one randomly selected wire per condition. The SEM inspection of the fracture surface revealed that the tip is practically thinned to zero (also known as knife edge fracture) by the local plastic deformation. This is illustrated in Fig.3. Only the fibers tested at $100{ }^{\circ} \mathrm{C}$ show welldefined fracture surface, see example in Fig.3(a). Other fibers exhibit "cut-edge" surface, see for example Fig.3 (b,c,d). However, this region is extremely localized (i.e. it occupies $\sim 50-100 \mu \mathrm{m}$ fiber length), and we expect that the thinning to the edge occurred at the very last phase of the deformation.

The diffuse necking region where the fiber is thinned, as measured by optical microscopy, extends up to $1 \mathrm{~mm}$, hence it represents the main contribution to the plastic deformation revealed by Fig.1(a). To recalculate the post-necking stress-strain (PNSS) relationship, we use the geometric parameters of the fractured fibers, see Fig.2(a), neglecting the "cut-edge" region. For some wires the location where necking originates was well defined, for others - this was not possible, hence we do not report the result for those wires. 
The generally accepted methodology of calculation of the true strain - true stress in tensile tests is valid within the region of the uniform elongation, and is thus limited by UTS. Once the neck is formed, the area of the thinned cross-section decreases faster than in the necking region of the specimen gauge. The use of cameras to record the evolution of cross-section area during a tensile test and consequent image processing is reported [25], but this method cannot be applied in the case of deformation of thin wires due to the lack of resolution of the optical system, in addition operating at elevated temperature imposes extra complexity.

As long as the significant part of the obtained engineering stress-strain curve represents the postnecking region, an assumption on the cross-section evolution is needed in order to obtain a set of PNSS curves, appropriate for the use as a constitutive law in FE analysis.

Here, the actual cross section area was assumed to decrease linearly and uniformly in shape with engineering strain from the moment of the neck formation until the wire failure. Hence, post-necking stress was calculated as the applied force divided by actual cross sectional area, and the post-necking strain was calculated as logarithm of the initial cross sectional area divided by actual one $[25,26]$ :

$\varepsilon=\ln \left(\frac{S_{0}}{S}\right)$

Hence, one can expect that the resulting post-necking strain would exceed the corresponding engineering value by about an order of magnitude. Indeed, as soon as the necking starts the segment of the wire involved in the deformation process is much shorter than the total gauge section length. The cross-section area at the moment of the neck initiation was assumed to be equal to $\pi D^{2} / 4$, here D is the initial wire diameter, neglecting the reduction due to uniform elongation (which is expected to be extremely small), and the final cross-section area $\mathbf{d}$ was measured by microscopy neglecting the edge area (see Fig. 2.). 


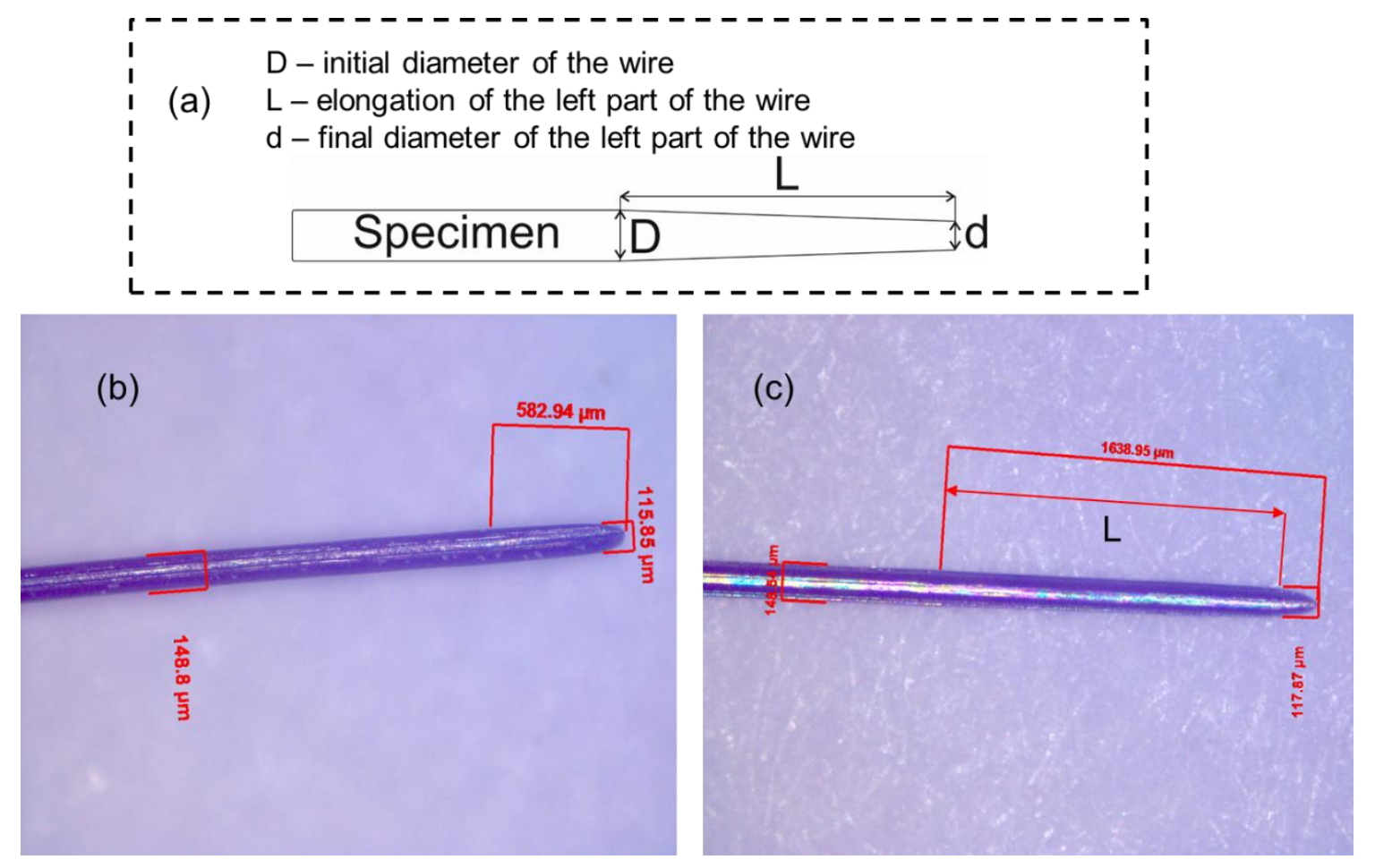

Fig.2. Illustration of the measurements done to deduce the geometric parameters of the wire after the tensile test. (a) definitions; $(b, c)$ left and right parts of the wire $\mathrm{C} 16$, tested at $600^{\circ} \mathrm{C}$. The presented pictures demonstrate the zoomed-out wires, whereas the actual position of the diffuse necking region was defined by proper zooming. The criteria for the location of the position of the diffuse necking onset was taken as $5 \%$ deviation from the mean diameter of the non-deformed wire. The dimensions provided on the figure reflect the technical capacity of the software, rather than the real accuracy of the identification of the geometrical parameters of the necking region. Based on the practice of comparison of LOM measurements with SEM measurements, the error on the LOM measurement is estimated to be about $5 \mu \mathrm{m}$. 

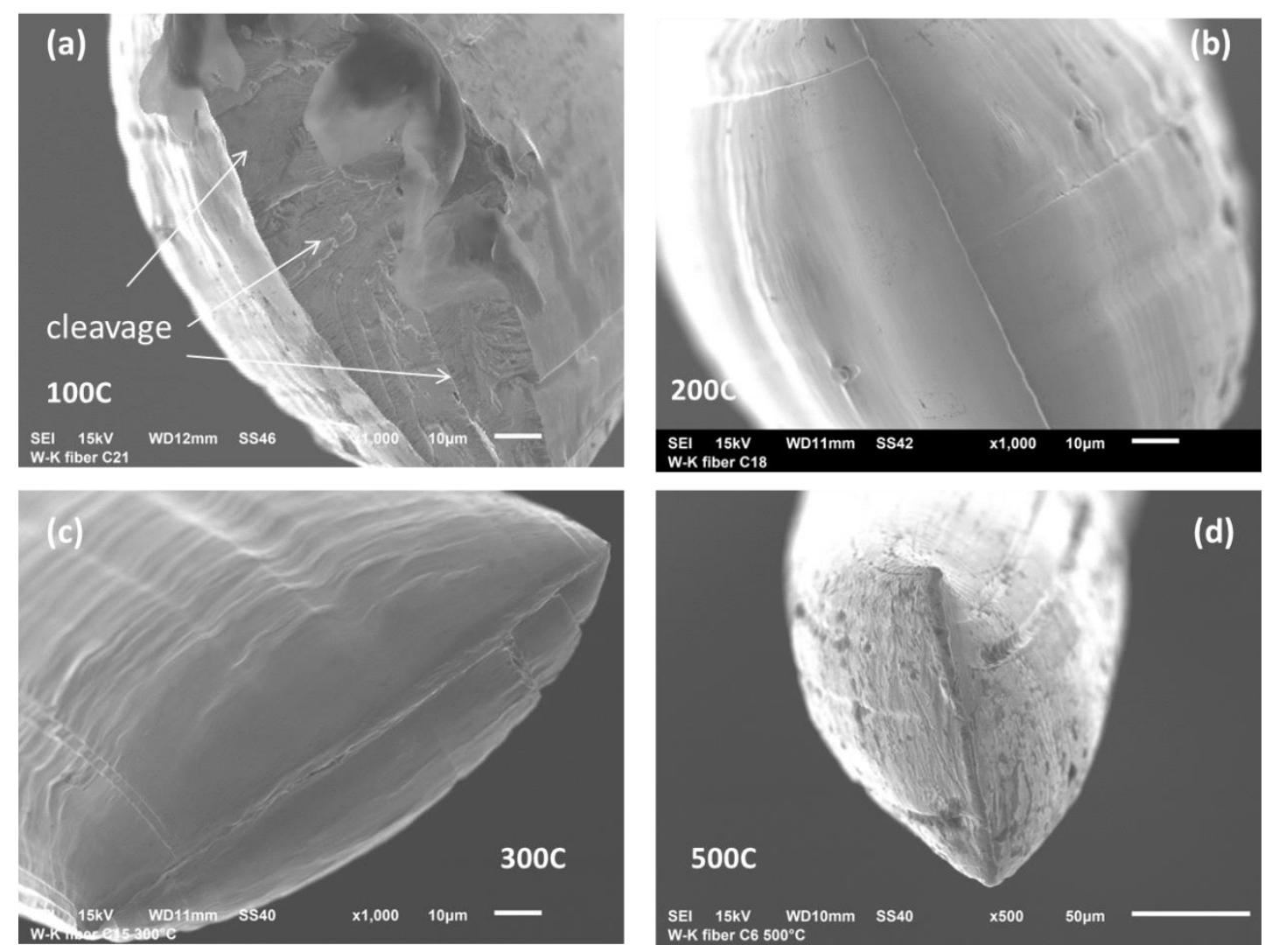

Fig.3. Comparison of the fracture surfaces after tensile tests of K-doped annealed fibers at $100 \mathrm{C}(\mathrm{a})$, $200 \mathrm{C}$ (b), 300C (c) and 500(d).

The examples of the reconstructed PNSS curves are presented in Fig.4 for 100, 200, 300 and $600{ }^{\circ} \mathrm{C}$. As one can see, there is no major difference between the ultimate recalculated stress (summarized in Fig.5a) and the engineering ultimate stress for the tests done at $100^{\circ} \mathrm{C}$. At higher temperatures, the recalculated stress exceeds the engineering one by a factor of 1.5 approximately. The comparison is presented in Table 2. Hence, the data reported earlier in [21], should be taken with a caution as long as the actual ultimate tensile stress is of concern. The actual post-necking strain, however, is much larger than the corresponding engineering value (see Fig.5(b)), naturally, given that the plastically deformed region is much shorter than the fiber gauge length. The obtained PNSS curves are summarized into datasets in Appendix A.1 so that it could directly be implemented as constitutive laws in the finite element codes.

Table 2. Comparison of the engineering and true ultimate stress.

\begin{tabular}{|l|l|l|l|l|}
\hline Temp, ${ }^{\circ} \mathrm{C}$ & $\begin{array}{l}\text { Engineering } \\
\text { UTS }\end{array}$ & Std. Error & $\begin{array}{l}\text { Corrected } \\
\text { UTS }\end{array}$ & $\begin{array}{l}\text { ratio } \\
\text { Corrected/Engineering } \\
\text { UTS }\end{array}$ \\
\hline 100 & 650 & 62 & 675 & 1.04 \\
\hline 200 & 401 & 40 & 581 & 1.45 \\
\hline 300 & 249 & 57 & 386 & 1.55 \\
\hline 500 & 130 & 31 & 195 & 1.5 \\
\hline 600 & 108 & 15 & 140 & 1.3 \\
\hline
\end{tabular}



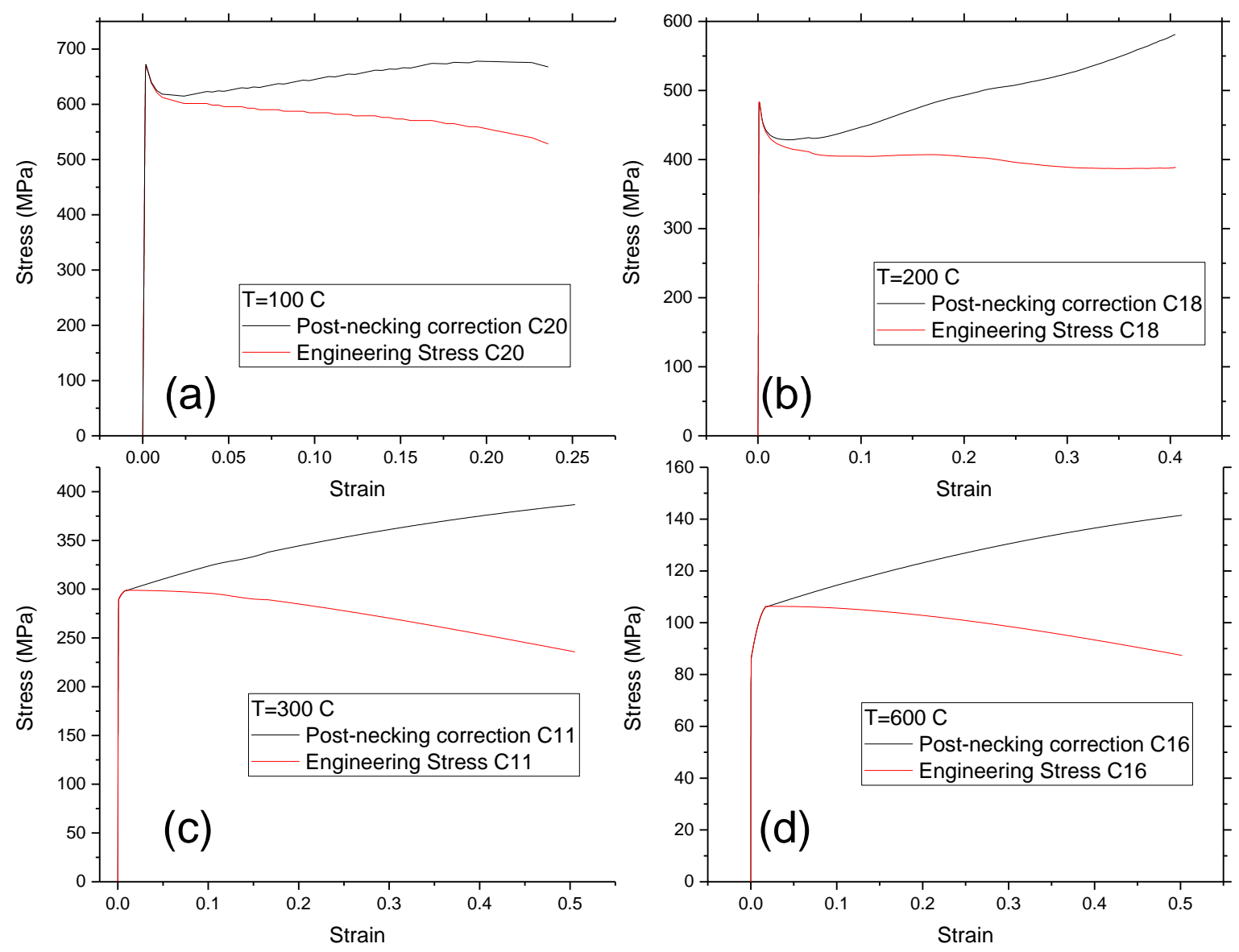

Fig.4. Engineering and corrected stress -strain curves for the tests performed at (a) $100{ }^{\circ} \mathrm{C}$, (b) 200 ${ }^{\circ} \mathrm{C}$, (c) $300{ }^{\circ} \mathrm{C}$ and (d) $600{ }^{\circ} \mathrm{C}$. The results for $500^{\circ} \mathrm{C}$ are not presented as they are found to be very similar to the data shown for $600^{\circ} \mathrm{C}$ test.

The results for different test temperatures are summarized in Fig.5(a). The beak on X-axis is introduced to underline the presence of the yield drop. Being plotted on the same figure, the TSS curves reveal that the work-hardening rate decreases as temperature exceeds $200^{\circ} \mathrm{C}$. This could be caused by a change in the deformation mechanism. It has to be mentioned that for the above discussed cases a uniform deformation in shape was assumed which might be different in reality. Non equiaxed deformation would lead to a three dimensional stress state and the actual stress curve is therefore likely to take a different shape. Detailed microstructural investigations are planned to determine the real shape of the deformation zone. Nevertheless, the presented results give the first indication of the real stress/strain conditions.

In order to clarify this assumption, we did a preliminary study by TEM using focus ion beam (FIB)-cut lamella extracted from the necking region of the wire deformed at $300^{\circ} \mathrm{C}$. It is very well known that FIB procedure induces the damage (by displacement of matrix atoms and forming point defect clusters) which generates extra pattern of defects. One possible way to remove this damage is to apply flash polishing procedure, which is by now well established for steels and iron-based alloys. 
Unfortunately, it is not yet fully developed for tungsten, and therefore the risk to lose the lamella is very high. Hence, for our preliminary study, we applied the conventional FIB-cut searching for dislocations and grain boundary patters which should be clearly distinct from the FIB-induced defects.

Fig.6 (a) and (b) show the necking region from where the TEM lamella was extracted. A preliminary TEM scan has revealed that the sample contains grain boundary-like interfaces with a size of about 12 micrometers. Inside those grain interiors, the isolated dislocation lines as well as dislocation networks and tangles are be observed, such as shown in Fig.6 (c) and (d). The occurrence of the grains might be either due to the non-completed recrystallization, thanks to potassium doping. But, it could also arise as a result of intensive plastic deformation which generates dislocation walls converting into low angle grain boundaries, as it was observed in bulk polycrystalline tungsten [27]. However, the clarification on the presence of grain boundaries requires further study, preferably by applying electron back scattering techniques as well as improvement of the FIB sample.

Nevertheless, thanks to this TEM insight, we indeed have evidence that at $300^{\circ} \mathrm{C}$ dislocations were generated and experienced intensive movement resulting in their multiplication, observed as dislocation tangles. Thus, at $300^{\circ} \mathrm{C}$ and above, the dislocation-mediated plastic deformation takes place. Below $300^{\circ} \mathrm{C}$, screw dislocations in tungsten are inactive, and the plastic deformation is ensured by the emission (from the open surface) and glide of edge dislocations, whose Peierls stress is much lower [28]. The limited plastic deformation, occurred by slip of edge dislocations emitted from the surface, is apparently possible because the high temperature annealing removed many of the pre-existing structural defects (like dislocations and grain boundaries) making the fiber to be a chain of single crystals connected by high angle grain boundaries. The onset of the deformation therefore corresponds to the critical stress required for the emission of edge dislocations from the free surface. While the necking region would be defined by the weakest grain boundary, which would obstruct the slip of the mobile edge dislocations thereby generating dislocation pile-ups and local stresses resulting in the diffuse necking.

Above $300^{\circ} \mathrm{C}$, both screw and edge dislocations move, and this results in the mutual interaction and multiplication-annihilation of the dislocations. Naturally, the capacity for the plastic deformation increases and the total strain before the fracture increases as well. From Fig.5(b), it follows that the actual (i.e. corrected accounting for post-necking deformation) plastic strain to fracture increases by a factor of two as temperature goes from $100^{\circ} \mathrm{C}$ to $300-600^{\circ} \mathrm{C}$. At the same time, the onset of complete $3 \mathrm{D}$ plastic deformation leads to the intensive thinning of the fiber such that it fractures at the stress of $200 \mathrm{MPa}$ in the temperature range $300-500^{\circ} \mathrm{C}$, and $100 \mathrm{MPa}$ at $600^{\circ} \mathrm{C}$. 

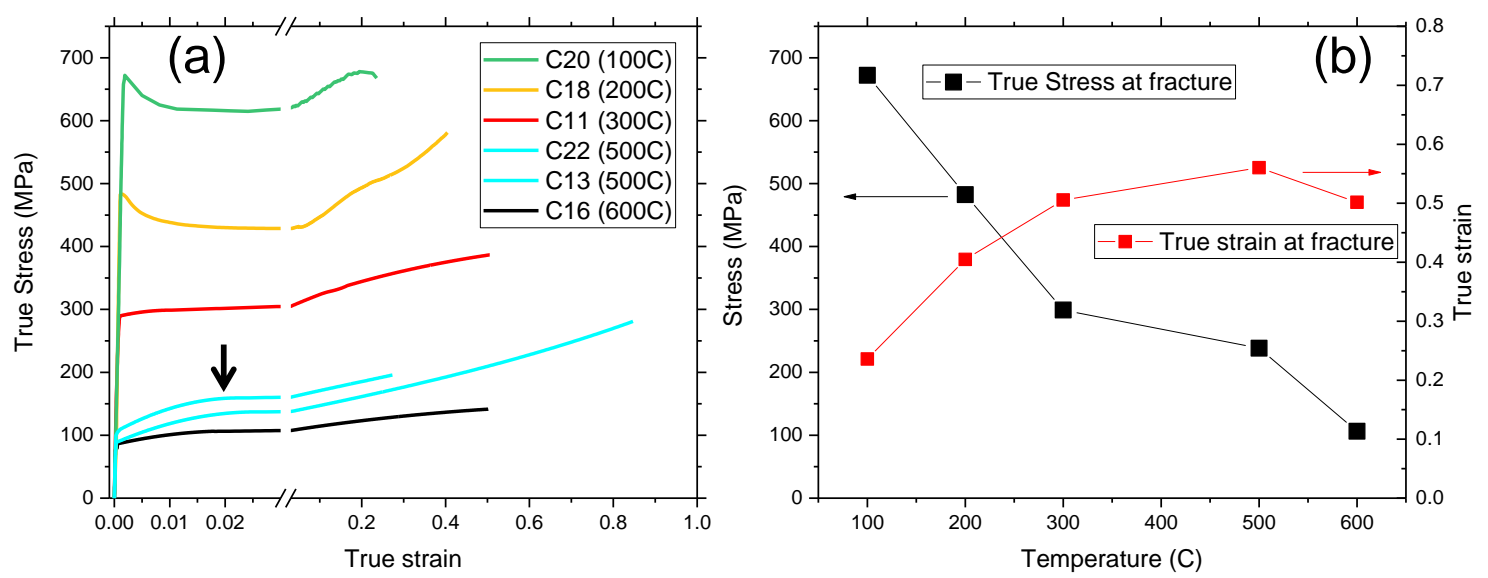

Fig.5. (a) Comparison of post-necking corrected stress - strain curves for different test temperature; (b) ultimate stress and strain, extracted from fig.(a), as a function of test temperature. The strain level for the onset of the diffuse necking is indicated in Fig.1, and also shown here in fig.(a) by the black arrow for the stress-strain curve obtained at $500^{\circ} \mathrm{C}$. 


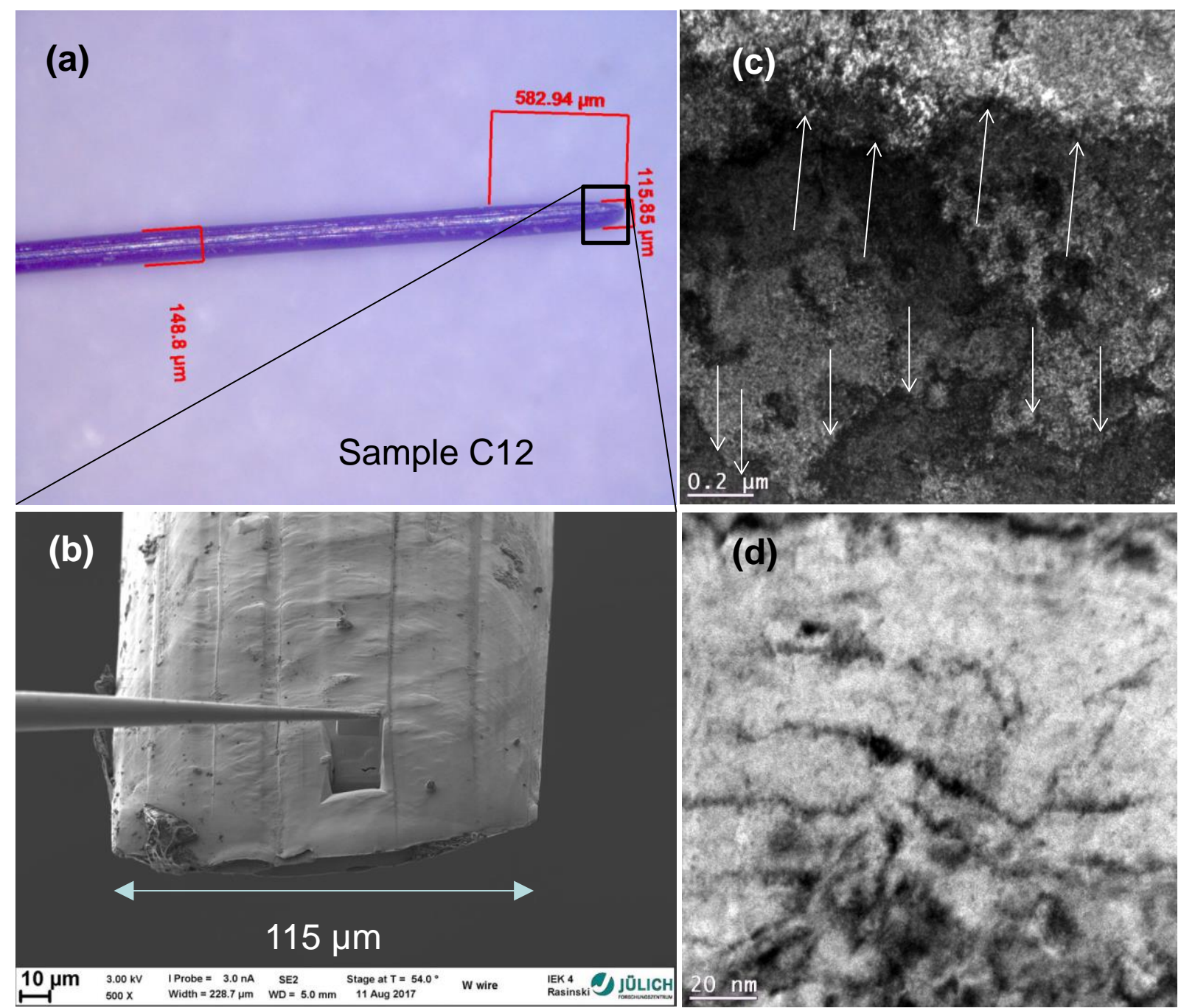

Fig.6. Microstructure of the of the fiber tested at $300^{\circ} \mathrm{C}$ : (a) LOM image; (b) SEM image of the extracted TEM lamella; (c) TEM image at small magnification showing the presence of the regions with different contrast; (d) TEM image at high magnification showing the presence of isolated dislocation lines and dislocation tangles. The white arrows on Fig.(c) indicate the grain boundary interfaces.

\section{Summary and conclusive remarks}

The results obtained here for the annealed K-doped fibers demonstrate that once the diffuse necking process emerges, the wires experience considerable plastic deformation in the necking region. This region can expand up to more than $1 \mathrm{~mm}$ along the wire. This implies that the local true strain at the moment of fracture can reach up to $50 \%$ at deformation temperature above $300^{\circ} \mathrm{C}$. However, even below this temperature, the local strain reaches $20-40 \%$ apparently at the expense of the plastic deformation ensured by the nucleation of dislocations at the wire surface. The SEM images clearly demonstrate the presence of wavy surface in the necking region, which is a signature of the dislocation slip. Given that tungsten exhibits rather large Peierls stress for the screw dislocations [28], it is likely that edge dislocations were contributing to the deformation below $300^{\circ} \mathrm{C}$.

The true stress, calculated on the basis of the assumption that the wire cross-section linearly decreases with the strain, exhibits nearly linear growths with the applied strain, and its slope 
decreases with the test temperature, turning the stress-strain to the Mecking-Kocks type relationship [29] above $300^{\circ} \mathrm{C}$. This is another indication for the onset of classical plastic deformation mechanism, where both processes dislocation movement and multiplication by dislocation bending and cross-slip are involved. Dedicated TEM experiments will be done in near future to investigate the actual microstructure, in terms of dislocation density and morphology, in the necking regions of the wires tested at different temperatures.

Besides the fine TEM measurements, the con-focal optical microscopy, as for instance was done in [30], would be a powerful tool to improve the accuracy of the quantitative measurements of the necking region. Some of the tested here fibers will be inspected by this techniques in future.

The actual fracture stress (i.e. corrected accounting for the post-necking deformation) decreases with temperature and goes down from 700 to $100 \mathrm{MPa}$ as the test temperature rises from 100 to 600 ${ }^{\circ} \mathrm{C}$. This drop is indeed very significant and it basically implies that the wires will impose very little resistance to the crack propagation if the fiber-based composite will be exposed to significant heats (around $2300^{\circ} \mathrm{C}$ ) resulting in a significant change in the wire microstructure. This gives therefore an indication for the forbidden temperature regime of tungsten fiber-reinforced tungsten composites.

\section{Acknowledgement}

This work has been carried out within the framework of the EUROfusion Consortium and has received funding from the Euratom research and training programme 2014-2018 under grant agreement No 633053. The views and opinions expressed herein do not necessarily reflect those of the European Commission. The work was partially supported by FOD grant of Belgium Government. The authors want to acknowledge support by OSRAM GmbH, Schwabmünchen, Germany for providing the tungsten wire and performing the annealing.

Appendix A.1. Stress- strain data for tungsten wires accounting for the post-necking correction.

\begin{tabular}{|r|r|r|r|r|r|}
\hline \multicolumn{2}{|l|}{ 100C, C20 } & \multicolumn{3}{l|}{ 200C, C18 } & \multicolumn{2}{l|}{ 300C, C11 } \\
\hline $\begin{array}{r}\text { True } \\
\text { strain }\end{array}$ & $\begin{array}{l}\text { True stress, } \\
\text { Mpa }\end{array}$ & $\begin{array}{l}\text { True } \\
\text { strain }\end{array}$ & $\begin{array}{l}\text { True stress, } \\
\text { Mpa }\end{array}$ & $\begin{array}{l}\text { True } \\
\text { strain }\end{array}$ & $\begin{array}{l}\text { True stress, } \\
\text { MPa }\end{array}$ \\
\hline 0 & 0 & 0 & 0 & 0 & 0 \\
\hline 0.0018 & 672 & 0.001 & 482 & 0.001 & 294 \\
\hline 0.005 & 640 & 0.01 & 437 & 0.06 & 313 \\
\hline 0.008 & 625 & 0.02 & 429 & 0.12 & 328 \\
\hline 0.014 & 618 & 0.04 & 430 & 0.18 & 341 \\
\hline 0.05 & 626 & 0.08 & 438 & 0.24 & 351 \\
\hline 0.1 & 645 & 0.12 & 456 & 0.3 & 361 \\
\hline 0.15 & 666 & 0.16 & 477 & 0.36 & 370 \\
\hline 0.2 & 677 & 0.2 & 493 & 0.42 & 378 \\
\hline 0.24 & 668 & 0.24 & 506 & 0.5 & 387 \\
\hline & & 0.28 & 517 & & \\
\hline & & 0.32 & 534 & & \\
\hline & & 0.36 & 554 & & \\
\hline & & 0.4 & 576 & & \\
\hline
\end{tabular}




\begin{tabular}{|c|c|c|c|c|c|}
\hline \multicolumn{2}{|c|}{$500 \mathrm{C}, \mathrm{C} 13$} & \multicolumn{2}{|c|}{$500 \mathrm{C}, \mathrm{C} 22$} & \multicolumn{2}{|c|}{ 600C, C16 } \\
\hline $\begin{array}{l}\text { True } \\
\text { strain }\end{array}$ & $\begin{array}{l}\text { True stress, } \\
\mathrm{MPa}\end{array}$ & $\begin{array}{l}\text { True } \\
\text { strain }\end{array}$ & $\begin{array}{l}\text { True stress, } \\
\mathrm{MPa}\end{array}$ & $\begin{array}{l}\text { True } \\
\text { strain }\end{array}$ & $\begin{array}{l}\text { True stress, } \\
\mathrm{MPa}\end{array}$ \\
\hline 0 & 0 & 0 & 0 & 0 & 0 \\
\hline 0.002 & 113 & $\begin{array}{r}2.80 \mathrm{E}- \\
04 \\
\end{array}$ & 88 & $\begin{array}{r}5.00 \mathrm{E}- \\
04 \\
\end{array}$ & 90 \\
\hline 0.008 & 137 & 0.015 & 128 & 0.01 & 101 \\
\hline 0.014 & 153 & 0.025 & 137 & 0.02 & 106 \\
\hline 0.024 & 160 & 0.1 & 147 & 0.1 & 114 \\
\hline 0.04 & 162 & 0.2 & 161 & 0.18 & 122 \\
\hline 0.1 & 170 & 0.3 & 177 & 0.26 & 128 \\
\hline 0.14 & 177 & 0.4 & 193 & 0.34 & 133 \\
\hline 0.18 & 182 & 0.5 & 210 & 0.42 & 138 \\
\hline 0.22 & 188 & 0.6 & 228 & & \\
\hline 0.27 & 195 & 0.7 & 248 & & \\
\hline & & 0.8 & 269 & & \\
\hline & & 0.84 & 281 & & \\
\hline
\end{tabular}

[1] V. Philipps, Tungsten as material for plasma-facing components in fusion devices, Journal of Nuclear Materials 415(1) (2011) S2-S9.

[2] A. Giannattasio, Z. Yao, E. Tarleton, S.G. Roberts, Brittle-ductile transitions in polycrystalline tungsten, Philosophical Magazine 90(30) (2010) 3947-3959.

[3] E. Lassner, W.D. Schubert, Tungsten - Properties, Chemistry, Technology of the Element, Alloys, and Chemical Compounds (Kluwer Academic / Plenum Publishers) (1999).

[4] J. Reiser, M. Rieth, B. Dafferner, A. Hoffmann, Charpy impact properties of pure tungsten plate material in as-received and recrystallized condition ( $1 \mathrm{~h}$ at 2000 degrees $\mathrm{C}(2273 \mathrm{~K})$ ), Journal of Nuclear Materials 442(1-3) (2013) S204-S207.

[5] S. Yih, C. Wang, Tungsten: Source, Metallurgy, Properties, and Applications (Springer Science+Business Media New York) (1979).

[6] V. Barabash, G. Federici, M. Rodig, L.L. Snead, C.H. Wu, Neutron irradiation effects on plasma facing materials, Journal of Nuclear Materials 283 (2000) 138-146.

[7] J.W. Coenen, S. Antusch, M. Aumann, W. Biel, J. Du, J. Engels, S. Heuer, A. Houben, T. Hoeschen, B. Jasper, F. Koch, J. Linke, A. Litnovsky, Y. Mao, R. Neu, G. Pintsuk, J. Riesch, M. Rasinski, J. Reiser, M. Rieth, A. Terra, B. Unterberg, T. Weber, T. Wegener, J.H. You, C. Linsmeier, Materials for DEMO and reactor applications-boundary conditions and new concepts, Physica Scripta T167 (2016).

[8] H. Sheng, G. Van Oost, E. Zhurkin, D. Terentyev, V.I. Dubinko, I. Uytdenhouwen, J. Vleugels, High temperature strain hardening behavior in double forged and potassium doped tungsten, Journal of Nuclear Materials 444(1-3) (2014) 214-219.

[9] D. Stork, P. Agostini, J.L. Boutard, D. Buckthorpe, E. Diegele, S.L. Dudarev, C. English, G. Federici, M.R. Gilbert, S. Gonzalez, A. Ibarra, C. Linsmeier, A. Li Puma, G. Marbach, P.F. Morris, L.W. Packer, B. Raj, M. Rieth, M.Q. Tran, D.J. Ward, S.J. Zinkle, Developing structural, high-heat flux and plasma facing materials for a near-term DEMO fusion power plant: The EU assessment, Journal of Nuclear Materials 455(1-3) (2014) 277-291.

[10] M. Rieth, S.L. Dudarev, S.M.G. de Vicente, J. Aktaa, T. Ahlgren, S. Autusch, D.E.J. Armstrong, M. Balden, N. Baluc, M.F. Barthe, W.W. Basuki, M. Battabyal, C.S. Becquart, D. Blagoeva, H. Boldyryeva, J. Brinkmann, M. Celino, L. Ciupinski, J.B. Correia, A. De Backer, C. Domain, E. Gaganidze, C. GarciaRosales, J. Gibson, M.R. Gilbert, S. Giusepponi, B. Gludovatzj, H. Greuner, K. Heinola, T. Hoschen, A. Hoffmann, N. Holstein, F. Koch, W. Krauss, H. Li, S. Lindig, J. Linke, C. Linsmeier, P. Lopez-Ruiz, H. Maier, J. Matejicek, T.P. Mishra, M. Muhammed, A. Munoz, M. Muzyk, K. Nordlund, D. Nguyen- 
Manh, J. Opschoor, N. Ordas, T. Palacios, G. Pintsuk, R. Pippan, J. Reiser, J. Riesch, S.G. Roberts, L. Romaner, M. Rosinski, M. Sanchez, W. Schulmeyer, H. Traxler, A. Urena, J.G. van der Laan, L. Veleva, S. Wahlberg, M. Walter, T. Weber, T. Weitkamp, S. Wurster, M.A. Yar, J.H. You, A. Zivelonghi, Recent progress in research on tungsten materials for nuclear fusion applications in Europe, Journal of Nuclear Materials 432(1-3) (2013) 482-500.

[11] J. Reiser, M. Rieth, Optimization and limitations of known DEMO divertor concepts, Fusion Engineering and Design 87(5-6) (2012) 718-721.

[12] C. Bachmann, G. Aiello, R. Albanese, R. Ambrosino, F. Arbeiter, J. Aubert, L. Boccaccini, D. Carloni, G. Federici, U. Fischer, M. Kovari, A. Li Puma, A. Loving, I. Maione, M. Mattei, G. Mazzone, B. Meszaros, I. Palermo, P. Pereslavtsev, V. Riccardo, P. Sardain, N. Taylor, S. Villari, Z. Vizvary, A. Vaccaro, E. Visca, R. Wenninger, Initial DEMO tokamak design configuration studies, Fusion Engineering and Design 98-99 (2015) 1423-1426.

[13] S.J. Zinkle, N.M. Ghoniem, Operating temperature windows for fusion reactor structural materials, Fusion Engineering and Design 51-52 (2000) 55-71.

[14] A.G. Evans, Perspective on the Development of High-Toughness Ceramics, J Am Ceram Soc 73(2) (1990) 187-206.

[15] J. Riesch, PhD thesis, Entwicklung und Charakterisierung eines wolframfaserverst Zarkten Wolfram-Verbundwerkstoffs Ph.D. thesis Technische Universität München URL http://mediatum.ub.tum.de/node?id=1106428 (2012).

[16] J. Riesch, M. Aumann, J.W. Coenen, H. Gietl, G. Holzner, T. Hoschen, P. Huber, M. Li, C. Linsmeier, R. Neu, Chemically deposited tungsten fibre-reinforced tungsten - The way to a mock-up for divertor applications, Nuclear Materials and Energy 9 (2016) 75-83.

[17] B. Jasper, S. Schoenen, J. Du, T. Hoeschen, F. Koch, C. Linsmeier, R. Neu, J. Riesch, A. Terra, J.W. Coenen, Behavior of tungsten fiber-reinforced tungsten based on single fiber push-out study, Nuclear Materials and Energy 9 (2016) 416-421.

[18] J. Riesch, J. Almanstotter, J.W. Coenen, M. Fuhr, H. Gietl, Y. Han, T. Hoschen, C. Linsmeier, N. Travitzky, P. Zhao, R. Neu, Properties of drawn W wire used as high performance fibre in tungsten fibre-reinforced tungsten composite, 37th Riso International Symposium on Materials Science 139 (2016).

[19] J. Riesch, A. Feichtmayer, M. Fuhr, J. Almanstötter, J.W. Coenen, H. Gietl, T. Höschen, C. Linsmeier, R. Neu, Tensile behaviour of drawn tungsten wire used in tungsten fibre-reinforced tungsten composites, Physica Scripta 2017 (2017) 014032.

[20] J. Riesch, J.Y. Buffiere, T. Hoschen, M. di Michiel, M. Scheel, C. Linsmeier, J.H. You, In situ synchrotron tomography estimation of toughening effect by semi-ductile fibre reinforcement in a tungsten-fibre-reinforced tungsten composite system, Acta Materialia 61(19) (2013) 7060-7071. [21] D. Terentyev, J. Riesch, S. Lebedev, A. Bakaeva, J.W. Coenen, Mechanical properties of asfabricated and $2300^{\circ} \mathrm{C}$ annealed tungsten wire tested up to $600^{\circ} \mathrm{C}$, Int J Refract Met H 66 (2017) 127-134.

[22] S. Leber, J. Tavernelli, D.D. White, R.F. Hehemann, Fracture Modes in Tungsten Wire, J LessCommon Met 48(1) (1976) 119-133.

[23] J. Riesch, Y. Han, J. Almanstotter, J.W. Coenen, T. Hoschen, B. Jasper, P. Zhao, C. Linsmeier, R. $\mathrm{Neu}$, Development of tungsten fibre-reinforced tungsten composites towards their use in DEMOpotassium doped tungsten wire, Physica Scripta T167 (2016).

[24] L. Cuddy, W. Leslie, Some aspects of serrated yielding in substitutional solid solutions of iron, Acta Metallurgica 20 (1972) 1157.

[25] M. Mahler, J. Aktaa, Approach for Determining Fracture Mechanical Properties from Tests on Small Size Specimens at Room Temperature, Procedia Materials Science 3 (2014) 434-439.

[26] Y. Ling, Uniaxial True Stress-Strain after Necking, AMP Journal of Technology 5 (1996) 37-48. [27] A. Dubinko, D. Terentyev, A. Bakaeva, K. Verbeken, M. Wirtz, M. Hernandez-Mayoral, Evolution of plastic deformation in heavily deformed and recrystallized tungsten of ITER specification studied by TEM, Int. Journal of Refractory Metals and Hard Materials 66 (2017) 105-115. 
[28] G. Bonny, D. Terentyev, A. Bakaev, P. Grigorev, D. Van Neck, Many-body central force potentials for tungsten, Model Simul Mater Sc 22(5) (2014) 053001.

[29] H. Mecking, U.F. Kocks, Kinetics of Flow and Strain-Hardening, Acta Metallurgica 29(11) (1981) 1865-1875.

[30] P. Zhao, J. Riesch, T. Hoschen, J. Almanstotter, M. Balden, J.W. Coenen, R. Himml, W. Pantleon, U. von Toussaint, R. Neu, Microstructure, mechanical behaviour and fracture of pure tungsten wire after different heat treatments, Int J Refract Met H 68 (2017) 29-40. 